\title{
Correspondence
}

We welcome letters to the Editor concerning articles which have recently been published. Such letters will be subject to the usual stages of selection and editing; where appropriate the authors of the original article will be offered the opportunity to reply.

Letters should normally be under 300 words in length, double-spaced throughout, signed by all authors and fully referenced. The edited version will be returned for approval before publication.

\section{Clinical and radiological aspects of idiopathic diabetic muscle infarction}

Sir,

We read with interest the article in the March 1999 issue entitled 'Clinical and radiological aspects of idiopathic diabetic muscle infarction' by Aboulafia et al. ${ }^{1}$ The authors reviewed 14 patients with diabetes mellitus referred during a five-year period for suspected soft-tissue sarcoma but who were subsequently found to have diabetic muscle infarction (DMI). They state that very few cases of DMI have been reported in literature, but almost concomitantly with the publication of this study, a second larger series including 21 patients with DMI over four years was reported by the same group. ${ }^{2}$ This suggests that DMI is possibly more common than is recognised, unless some patients of the first series were included in the second. It should be noted that DMI does not always present as a soft-tissue sarcoma but can also mimic an infection, as we and others recently reported in young diabetic patients. ${ }^{3,4}$ In our case, MRI played an important role in the diagnosis. A hypersignal of the muscle was found on T2-weighted images whereas T1weighted images after gadolinium showed a dark abscess-like lesion containing enhanced linear signal infiltrates, which was surrounded by an enhanced rim. Similar images have also been reported by Jelinek et al. ${ }^{2}$ We agree with the latter authors that, in some patients, a typical clinical presentation with sudden painful swelling of a leg in a diabetic patient, associated with characteristic MRI findings, may allow diagnosis without the need for other expensive and unnecessary investigations (CT, radioisotope scan, biopsy) such as those performed by Aboulafia et al. ${ }^{1}$

F. HEUREUX, MD

E. DELGRANGE, MD

J. DONCKIER, MD, PhD

University Hospital UCL of Mont-Godinne

Yvoir, Belgium.

1. Aboulafia AJ, Monson DK, Kennon RE. Clinical and radiological aspects of idiopathic diabetic muscle infarction. J Bone Joint Surg [Br] 1999;81-B:323-6.

2. Jelinek JS, Murphey MD, Aboulafia AJ, et al. Muscle infarction in patients with diabetes mellitus: MR imaging findings. Radiology 1999; 211:241-7.

3. Heureux F, Nisolle JF, Delgrange E, Donckier J. Diabetic muscle infarction: a difficult diagnosis suggested by magnetic resonance imaging. Diabetic Med 1998;15:619-22.

4. Sagar M, Bowerfind W, Wighley F. A man with diabetes and a swollen leg. Lancet 1999;353:116.

(C1999 British Editorial Society of Bone and Joint Surgery

0301-620X/99/610579 \$2.00

J Bone Joint Surg [Br] 1999;81-B:1083-5.

VOL. 81-B, No. 6, NOVEMBER 1999

\section{Author's reply:}

Sir,

We thank Drs Heureux, Delgrange and Donckier for their comments on our article. ${ }^{1}$ This described 14 patients with diabetic muscle infarction (DMI) who were referred to one of two orthopaedic oncologists at a single institution over five years for evaluation of a suspected sarcoma. During an overlapping period of four years Jelinek et $\mathrm{al}^{2}$ reviewed 21 cases of DMI collected from six institutions, including six from our series. The two articles described 29 cases in all. The purpose of our paper was "to point out that the condition may simulate a sarcoma and to outline a rational approach for diagnosis and treatment..", whereas the article by Jelinek et al $^{2}$ described the MRI findings. We agree that the latter investigation may obviate other expensive and unnecessary procedures.

The inclusion of an infectious process in the differential diagnosis of a patient with DMI and the possible limitations of MRI in establishing the diagnosis are discussed in our paper. In cases in which the physician is uncertain of the diagnosis of infection or DMI, and feels confident that the patient does not have a sarcoma, a needle biopsy may be indicated. Early in our study, one patient suspected of having a DMI based on clinical and MRI presentation underwent a needle biopsy and frank pus was obtained. We recognise that not all radiologists and orthopaedic surgeons will have the same level of confidence and experience in diagnosing DMI on the clinical and MRI evidence only, and the decision to perform a needle biopsy in selected cases may be justified.

A. J. ABOULAFIA, MD

Emory School of Medicine

Atlanta, USA.

1. Aboulafia AJ, Monson DK, Kennon RE. Clinical and radiological aspects of idiopathic diabetic muscle infarction. J Bone Joint Surg [Br] 1999;81-B:323-6.

2. Jelinek JS, Murphey MD, Aboulafia AJ, et al. Muscle infarction in patients with diabetes mellitus: MR imaging findings. Radiology 1999; 211:241-7.

\section{Ultrasound screening for hips at risk in developmental dysplasia}

Sir,

I read with interest the article by Paton et $\mathrm{al}^{1}$ in the March issue entitled 'Ultrasound screening for hips at risk in developmental dysplasia.' A central issue is a comparison of the screening of the at-risk group at eight to nine weeks with that of the clinically unstable group within two weeks of birth. Statistical inferences are then drawn despite the fact that these two groups were screened at different ages. The authors refer to the paper of Marks, Clegg and Al-Chalabi ${ }^{2}$ which showed that $90 \%$ of cases of apparent dysplasia at birth will resolve by eight to nine weeks. By this rationale it is possible that screening of the at-risk group at the same time as the clinically unstable group could have yielded another 99 cases!

It would be interesting to know the outcome of the group-II and group-III hips and if they were included in the analysis. We have made a recent study in which 323 at-risk infants were screened and 90 grade-II hips were identified. ${ }^{3}$ As with findings reported in the literature these all resolved spontaneously by eight to nine 
weeks. In our study all type III-IV hips were splinted with the Aberdeen splint. Despite the best efforts of Berman and Klener$\operatorname{man}^{4}$ and Castelein et $\mathrm{al}^{5}$ we still cannot be certain of the natural development of all hips identified as abnormal by ultrasound, particularly as identification of an 'abnormal' hip with screening begs a moral obligation to 'treat'.

P. WILLIAMS, BSc, FRCS

The Robert Jones and Agnes Hunt Orthopaedic Hospital Oswestry, UK.

1. Paton RW, Srinivasan MS, Shah B, Hollis S. Ultrasound screening for hips at risk in developmental dysplasia: is it worth it? J Bone Joint Surg [Br] 1999;81-B:255-8

2. Marks DS, Clegg J, Al-Chalabi AN. Routine ultrasound screening for neonatal hip instability: can it abolish late-presenting congenital dislocation of the hip? J Bone Joint Surg [Br] 1994;76-B:534-8.

3. Williams PR, Bishay M, Jones DA. Avascular necrosis and the Aberdeen splint in the management of neonatal hip instability. J Bone Joint Surg [Br] 1999;81-B:1023-8.

4. Berman L, Klenerman L. Ultrasound screening for hip abnormalities: preliminary findings in 1001 neonates. BMJ 1986;293: 719-22.

5. Castelein RM, Sauter AJ, de Vlieger M, van Linge B. Natural history of ultrasound hip abnormalities in clinically normal newborns. J Paediatr Orthop 1993;2:115-21.

\section{Authors' reply:}

Sir,

We thank Mr Williams for his interest. He raises the dilemma regarding the place of ultrasound assessment in the diagnosis and treatment of developmental dysplasia of the hip (DDH).

There are two schools of thought, namely the 'treat from birth' and the 'expectant' in the management of abnormalities detected by ultrasound. Advocates of the former feel that all ultrasound abnormalities are pathological and should be treated if diagnosed. This has led to treatment rates of $9.0 \%$. ${ }^{1}$ The expectant group takes the view that most abnormalities at birth are physiological and should improve, resulting in rates of splintage as low as $0.18 \%$. $^{2}$ Thus the treat-from-birth group may have treatment rates 45 times more than those of the expectant group.

The treat-from-birth group still encounter children with 'late' hip dislocation. We consider that most ultrasound abnormalities at birth represent physiologically immature hips which mature in time, and that the splintage of these is unnecessary. Only those with clinical instability of the hip should be screened at birth since this group should be closely monitored. 'At-risk hips' can be safely left until nine weeks since the risk of dislocation is very low if the hip is stable at birth. Logistically, it keeps the numbers requiring ultrasonographic assessment to manageable levels.

In our unit all stable hips with dysplasia are reviewed by serial ultrasound. Type-II hips are not currently treated and appear to resolve. Type-III hips which are stable on dynamic ultrasound assessment are reviewed by serial ultrasound. If subluxation or dysplasia persists after 12 weeks the hip is splinted by a Pavlik harness, since these hips may progress to late dislocation. This regime appears to be successful since the current rate of surgery for late dislocation in this unit is approximately 0.5 per 1000 live births.

A recent study by Paton and Jari was presented at the British Orthopaedic Association Meeting in Glasgow in September 1999. Hip instability at birth was assessed by serial ultrasound but not treated. It was found that $73 \%$ of hips developed normally, $87 \%$ of hips stabilised spontaneously and that $13 \%$ of hips continued with persistent dysplasia. Instability and dysplasia were treated by a harness after several weeks of observation.

We do not feel a moral obligation to 'treat' all abnormalities observed by ultrasound. Most unstable hips stabilise; on ultrasound examination most dysplastic hips are immature, not patho- logical, and develop without treatment. The overtreatment of apparently abnormal hips with splintage may cause the rare but disastrous complication of avascular necrosis of the capital femoral epiphysis.

R. W. PATON, FRCS Orth

M. S. SRINIVASAN, FRCS Orth

Blackburn Royal Infirmary

Blackburn, UK

1. Ganger R, Grill F, Leodolter S. Ultrasound screening of the hip in newborns: results and experience. J Pediatr Orthop Part B 1992;1: 245-9.

2. Andersson JE, Funnemark P. Neonatal hip instability: screening with anterior-dynamic ultrasound method. J Pediatr Orthop 1995;15: $322-4$

\section{Screw versus suture fixation of Mitchell's osteotomy}

Sir,

I read with interest the article by Calder et al $^{1}$ in the July 1999 issue entitled 'Screw versus suture fixation of Mitchell's osteotomy' and agree that fixation of Mitchell's osteotomy by screw is stronger than that with sutures.

I have tried using fixation of Mitchell's osteotomy by a screw in two cases without success. The difficulty was the placement of the screw. To obtain stable fixation of the osteotomy, the screw should preferably pass perpendicular to the osteotomy. This is almost impossible without going too proximal and through the head of the metatarsal. Fixation by screw will only be possible when the osteotomy is more proximal than was recommended by Mitchell and when it is oblique rather than perpendicular to the shaft of the first metatarsal. In 1958, after extensive experience with this procedure, Mitchell et $\mathrm{al}^{3}$ recommended that the osteotomy should be done at the level of the neck of the metatarsal where there is cancellous bone, to allow better healing. They also found that the desired position of the toe would be more difficult to maintain when the osteotomy is in the shaft. I would welcome the authors' comments on this.

A. A. FARAJ, FRCS Ed, MCh Orth

Bradford Royal Infirmary

Bradford, UK.

1. Calder JDF, Hollingdale JP, Pearse MF. Screw versus suture fixation of Mitchell's osteotomy: a prospective, randomised study. J Bone Joint Surg [Br] 1999;81-B:621-4.

2. Calder JDF, Hollingdale JP. Measurement of strength and stability of suture versus AO screw fixation of Mitchell's osteotomy: a cadaveric study. The Foot 1997;7:220-3.

3. Mitchell CL, Fleming JL, Allen R, Glenney C, Sanford GA. Osteotomy-bunionectomy for hallux valgus. J Bone Joint Surg [Am] 1958;40-Ä:41-60

\section{Author's reply:}

Sir,

I thank Mr Faraj for his comments. We agree with him that placement of the screw is crucial for the stability of the osteotomy. We would not recommend that the osteotomy is made obliquely because this may further shorten the first ray. An osteotomy more proximal than that described by Mitchell et al may also increase the risk of nonunion. Our biomechanical study, however, showed that such modifications are not necessary to obtain satisfactory stability with a screw. ${ }^{1}$

In our experience the use of a screw is easier than the techniques required for suture fixation. Kirschner wires and polydioxanone pins likewise rely upon accurate placement for fixation of Mitchell's osteotomy. During all the procedures in our clinical study, the metatarsophalangeal joint was inspected to ensure that the screw was not in the joint and we believe that experience 
allows accurate insertion of the screw with stability of the osteotomy. In a case report, Bonner described using a jig to ensure accurate placement of a Herbert screw for fixation of Mitchell's osteotomy. ${ }^{2}$ This suggestion is interesting since it may also eliminate skin irritation caused by the prominent head of an AO screw which we reported in some patients.

J. D. F. CALDER, FRCS

Kew,

Surrey, UK.

1. Calder JDF, Hollingdale JP. Measurement of strength and stability of suture versus AO screw fixation of Mitchell's osteotomy: a cadaveric study. The Foot 1997;7:220-3.

2. Bonner AC, Jr. Rigid internal fixation of the Mitchell-Hawkins osteotomy/bunionectomy with the Herbert bone screw. J Foot Surg 1986;25:390-3.

Sir

We read with interest the paper by Calder et al ${ }^{1}$ in the July 1999 issue entitled 'Screw versus suture fixation of Mitchell's osteotomy' and agree with their conclusions. We note that the mean reduction in length of the first metatarsal was 4 to $5 \mathrm{~mm}$. There was no mention of transfer lesions as a possible sequel of this. We have recently reported a study on the treatment of intractable plantar keratosis which showed that shortening the second metatarsal by up to $4 \mathrm{~mm}$ produced clinical or pedobarographically proven transfer lesions in $70 \%$ of patients. ${ }^{2}$ If studies on foot pressure were performed in the patients of Calder et al then similar results may be found.

N. J. HARRIS, FRCS

J. CHELL, FRCS

P. R. M. BLACK, FRCS

Northern General Hospital

Sheffield, UK.
1. Calder JDF, Hollingdale JP, Pearse MF. Screw versus suture fixation of Mitchell's osteotomy: a prospective, randomised study. J Bone Joint Surg [Br] 1999;81-B:621-4.

2. Harris NJ, Betts RP, Smith TWD. A prospective clinical and pedobarographic evaluation of metatarsal shortening in the treatment of intractable plantar keratosis. Foot \& Ankle Surg 1998;4:201-5.

\section{Author's reply:}

Sir,

I thank Messrs Harris, Chell and Black for their interest. We acknowledge their reports of transfer lesions secondary to shortening of the second metatarsal in patients with intractable plantar keratosis ${ }^{1}$ and also recognise that shortening the first metatarsal may predispose to transfer metatarsalgia. We did not purposefully plantar flex the distal fragment to compensate for shortening as has been described by Bonner. ${ }^{2}$ No transfer lesions were found in our patients at follow-up. There are at least two explanations for this. Either transfer lesions do not occur, or the length of followup was too short for such lesions to become clinically apparent. We agree that pedobarographic evaluation of our patients may identify which of these explanations is accurate.

\author{
J. D. F. CALDER, FRCS \\ Kew,
}

Surrey, UK.

1. Harris NJ, Betts RP, Smith TWD. A prospective clinical and pedobarographic evaluation of metatarsal shortening in the treatment of intractable plantar keratosis. Foot \& Ankle Surg 1998;4:201-5.

2. Bonner AC, Jr. Rigid internal fixation of the Mitchell-Hawkins osteotomy/bunionectomy with the Herbert bone screw. J Foot Surg 1986;25:390-3. 